\title{
Spatial Packing, Cranial Base Angulation, and Craniofacial Shape Variation in the Mammalian Skull: Testing a New Model Using Mice
}

\section{Citation}

Lieberman, Daniel E., Benedikt Hallgrímsson, Wei Liu, Trish E. Parsons, Heather A. Jamniczky. 2008. Spatial packing, cranial base angulation, and craniofacial shape variation in the mammalian skull: Testing a new model using mice. Journal of Anatomy 212(6): 720-735.

\section{Published Version}

doi:10.1111/j.1469-7580.2008.00900.x

\section{Permanent link}

http://nrs.harvard.edu/urn-3:HUL.InstRepos:3716642

\section{Terms of Use}

This article was downloaded from Harvard University's DASH repository, and is made available under the terms and conditions applicable to Other Posted Material, as set forth at http:// nrs.harvard.edu/urn-3:HUL.InstRepos:dash.current.terms-of-use\#LAA

\section{Share Your Story}

The Harvard community has made this article openly available.

Please share how this access benefits you. Submit a story.

\section{Accessibility}




\title{
Spatial packing, cranial base angulation, and craniofacial shape variation in the mammalian skull: testing a new model using mice
}

\author{
Daniel E. Lieberman, ${ }^{1, *}$ Benedikt Hallgrímsson, ${ }^{2, *}$ Wei Liu, ${ }^{2}$ Trish E. Parsons ${ }^{2}$ and Heather A. Jamniczky ${ }^{2}$ \\ ${ }^{1}$ Departments of Anthropology and Organismic \& Evolutionary Biology, Harvard University, Cambridge MA, USA \\ ${ }^{2}$ Department of Cell Biology and Anatomy, and The Bone and Joint Institute, University of Calgary, Calgary, Alberta, Canada
}

\begin{abstract}
The hypothesis that variation in craniofacial shape within and among species is influenced by spatial packing has a long history in comparative anatomy, particularly in terms of primates. This study develops and tests three alternative models of spatial packing to address how and to what extent the cranial base angle is influenced by variation in brain and facial size. The models are tested using mouse strains with different mutations affecting craniofacial growth. Although mice have distinctive crania with small brains, long faces, and retroflexed cranial bases, the results of the study indicate that the mouse cranial base flexes to accommodate larger brain size relative to cranial base length. In addition, the mouse cranial base also extends, but to a lesser degree, to accommodate larger face size relative to cranial base length. In addition, interactions between brain size, face size, and the widths and lengths of the components of the cranial base account for a large percentage of variation in cranial base angle. The results illustrate the degree to which the cranial base is centrally embedded within the covariation structure of the craniofacial complex as a whole.
\end{abstract}

Key words basicranium; cranial base; integration; mouse; spatial packing.

\section{Introduction}

The skull is both a highly modular and a highly integrated structure. Anatomists have traditionally divided the skull into three primary units: the face, neurocranium and basicranium (each comprising further sub-modules). These units are known to be partially independent because of their distinct embryonic origins, different processes of development, and disparate functional roles (de Beer, 1937; Cheverud, 1982, 1996; Lieberman et al. 2000a). Despite their independence, these three major regions interact considerably during development via many processes to generate a highly integrated whole. How developmental changes to these cranial modules and how their processes of integration lead to predictable variations in overall skull form, both within and among species, are questions of considerable and longstanding interest.

This study focuses on the role of the basicranium, particularly the angle of the cranial base, in terms of integrating development and influencing overall craniofacial

\section{Correspondence}

Daniel E. Lieberman, 11 Divinity Avenue, Cambridge MA, 02138,

USA. T: +1617 4955499; F: +1 617 4968991;

E: danlieb@fas.harvard.edu

*These authors contributed equally to this work.

Accepted for publication 15 February 2008 form. There are three reasons to hypothesize that the basicranium may be particularly important in this regard. First, whereas facial and neurocranial growth occur through processes of intramembranous ossification around various organs and spaces (the brain, eyes, pharyngeal spaces and so on), the basicranium grows mostly via endochondral ossification, at first from a set of cartilagenous precursors and then from expansion within the synchondroses, which resemble growth plates in many respects. Thus, basicranial growth may be under more intrinsic control than the intramembranous parts of the face and neurocranium (Scott, 1958). Secondly, the basicranium attains adult size earlier in ontogeny than the neurocranium and face (Bastir et al. 2006) and thus may constrain subsequent aspects of neurocranial and facial growth. Finally, the basicranium comprises the central axis of the skull with the brain and neurocranium growing above, and the face growing below, and it provides all the necessary foramina through which the brain connects to the face and the body. Thus, basicranial growth is closely related to the size and shape of the endocranial fossae, the position of the superior and posterior margins of the face, and the relative orientation of midline structures relative to each other. Because of these properties, many researchers have speculated that the basicranium plays an especially important role in influencing overall skull growth (e.g. de Beer, 1937; Weidenreich, 1941; Biegert, 1957, 1963; Hofer, 1960; Moss 


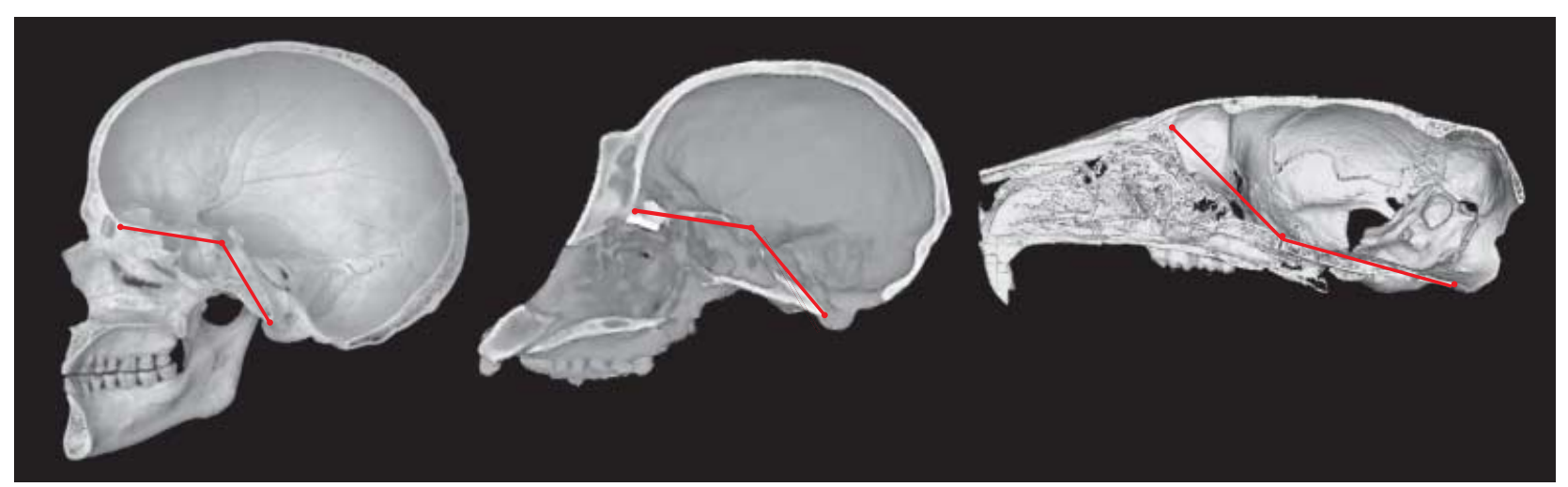

Fig. 1 Midsagittal sections through human (H. sapiens), pygmy chimpanzee (Pan paniscus), and mouse (Mus musculus) crania showing differences in orientation between prechordal and postchordal cranial base (CBA1). Note that the mouse is retroflexed $\left(C B A 1\right.$ is greater than $\left.180^{\circ}\right)$. See text for landmark details.

\& Young, 1960; Hofer \& Spatz, 1963; Enlow, 1990; Ross \& Ravosa, 1993; Ross \& Henneberg, 1995; Lieberman, 1998; Lieberman et al. 2000a,b; McCarthy \& Lieberman, 2001; Ross et al. 2004; Bastir \& Rosas, 2006; Bastir et al. 2006).

Of the many aspects of basicranial variation that potentially influence overall skull form, the orientation of the anterior versus posterior parts of the cranial base in the midsagittal plane (the cranial base angle, CBA), is of special importance for mammalian evolution in general and primate evolution in particular. There are many ways to define and measure CBA, but most formulations quantify the midline angle between the prechordal and postchordal portions of the cranial base that arise, respectively, from endochondral precursors anterior and posterior to the termination of the notochord at the base of the hypophyseal fossa (for review, see Lieberman \& McCarthy, 1999). In most mammals (see Fig. 1), CBA is relatively flat or obtuse. In some mammals, such as mice, CBA is actually retroflexed (greater than $180^{\circ}$ when measured from the ventral aspect). But in humans, the CBA is highly flexed, with such an acute angle between the pre- and postchordal portions of the basicranium that much of the face lies directly inferior to the anterior cranial fossa. CBA varies considerably in non-human primates, with the ape configuration approximately intermediate between humans and other mammals in terms of the degree of basicranial flexion (Fig. 1).

Variation in CBA raises many questions. At the most proximate level, to what extent does variation in CBA result from hinge-like flexion or extension within synchondroses, and/or from drift in which resorption and deposition on opposite surfaces of the endocranial fossae cause rotations (for review, see Lieberman et al. 2000b)? More generally, how does variation in CBA participate in terms of overall craniofacial integration (integration is defined here as the genetic and epigenetic processes that cause coordinated changes among different units of the skull that result in a distinctive pattern of covariation and correlation)? And, ultimately, how might variation in CBA be adaptively significant?
Although the proximate bases for variation in $C B A$ are important, we focus here on the role of CBA in craniofacial integration because understanding how and to what extent $C B A$ variation mediates interactions between the face and neurocranium is necessary for evaluating selective hypotheses about a wide range of craniofacial variation. We specifically address the hypothesis of spatial packing, the most widely accepted and best-documented model that explains some proportion of variation in CBA. The basic idea behind the spatial packing model is that because the brain grows on top of the cranial base, a more flexed (or less extended) cranial base helps to accommodate a larger volume of brain without having to change the width and length of the cranial base. The hypothesis has a long history (Virchow, 1857; Bolk, 1910; Weidenreich, 1941; Hofer, 1960), but was formulated most explicitly by Biegert (1957, 1963), and subsequently expanded upon somewhat informally (DuBrul \& Laskin, 1961; Vogel, 1964; Gould, 1977; Enlow, 1990). The first statistically rigorous and comparative test of the spatial packing model was by Ross \& Ravosa (1993), who used radiographs from a broad interspecific sample of primates to measure the correlation between CBA (measured as the angle between the presphenoid plane and the basioccipital clivus) and the Index of Relative Encephalization (IRE, computed as endocranial volume ${ }^{0.33} /$ cranial base length). Ross \& Ravosa (1993) found that IRE and CBA are highly correlated among primates $(r=0.645 ; P<0.001)$. Many studies have followed upon Ross \& Ravosa (1993), including Ross \& Henneberg (1995), Spoor (1997), Lieberman \& McCarthy (1999), Strait (1999), Lieberman et al. (2000b), McCarthy (2001), Ross et al. (2004). These studies have replicated Ross \& Ravosa's (1993) basic conclusions, but differ slightly as to the extent to which the highly flexed human cranial base can be predicted by spatial packing.

In spite of broad support for spatial packing, it is important to note that IRE explains at best about $40 \%$ of the variation of CBA among primates, even after accounting for 
phylogenetic relatedness (Lieberman et al. 2000b). Other factors must account for a substantial proportion of CBA variation. Ontogenetic data illustrate this problem. During much of human fetal growth, when the brain expands most rapidly, the cranial base actually extends by approximately 9-15 ${ }^{\circ}$ rather than flexes (Jeffery \& Spoor, 2002, 2004; Jeffery, 2003). In many non-human primates such as chimpanzees, the cranial base extends by as much as $15^{\circ}$ during ontogeny after the brain has ceased to grow (Lieberman \& McCarthy, 1999). Consequently, it is possible that the cranial base also helps accommodate spatial packing of the face. Because the anterior cranial base comprises most of the roof of the orbits, and because the back of the face is always nearly perpendicular to the orientation of the orbits, variations in CBA cause the entire face to rotate as a 'block' relative to the rest of the cranium (McCarthy \& Lieberman, 2001). Thus, a more extended cranial base rotates the face dorsally, possibly to help accommodate a longer, more prognathic face without impinging upon the pharynx (Lieberman, 1998, 2000). In addition, more prognathic animals may have a more extended anterior cranial base because the orientation of the cribriform plate, a part usually of the anterior cranial base, is nearly $90^{\circ}$ to the anterior midsagittal margin of the face (Enlow \& Azuma, 1975; Ravosa \& Shea, 1994; McCarthy, 2001). Such 'facial' packing, however, is not supported strongly. Although the orientation of the anterior cranial base and orbits is highly correlated (Dabelow, 1929; Ravosa, 1991a,b, McCarthy \& Lieberman, 2001), the orientation of the palate and the anterior cranial base is poorly correlated after controlling for the effects of the orientation of the orbital axis (Ross \& Ravosa, 1993). Moreover, anterior cranial base and orbital orientation are significantly correlated in taxa such as haplorhines (monkeys and tarsiers) with convergent orbits, but not in other taxa such as such as strepsirhines (lemurs, lorises and galagos) with divergent orbits (McCarthy \& Lieberman, 2001).

Finally, it is reasonable to hypothesize that factors other than spatial packing also influence variation in CBA. One possibility is that a more flexed cranial base sets up a more spherical brain, thus minimizing the length of connections among different parts of the brain (Hofer, 1969; Ross et al. 2004). In addition, variations in CBA may help accommodate variations in posture and/or orbital orientation. Because the floor of the anterior cranial fossa is also the roof of the orbits, CBA variations alter the orientation of the orbits relative to the rest of the cranium, including the foramen magnum. Although one would predict more orthograde primates to have more flexed cranial bases, this relationship is not significant when variations in relative brain size are taken into consideration (Strait \& Ross, 1999). Finally, the unique and highly flexed CBA in humans has been proposed to be an adaptation for speech by causing the larynx to descend relative to the palate (Laitman \& Crelin, 1976). This hypothesis, however, is problematic because
CBA and larynx position are uncorrelated (Lieberman \& McCarthy, 1999).

It should also be noted that a basic challenge for evaluating hypotheses about CBA variation within and between species is the multiplicity of factors that influence the midsagittal angle of the cranial base. Variations in CBA may derive from some degree of intrinsic regulation of cartilage growth within the synchondroses, and by a host of epigenetic interactions between the cranial base, the brain and its associated tissues (e.g. the dural bands), the facial skeleton, and the many organs and spaces of the face (e.g. the oropharynx, nasopharynx, eyes, and oral cavity). Interspecific studies of closely related species such as primates provide only a limited means of hypothesis testing because many of the factors that potentially influence CBA do not vary independently among species. Another complication is that although cranial base angulation is usually measured with a single angle, CBA, this variable actually summarizes angles at three synchondroses between many different basicranial components that, together, make up the posterior, middle and anterior cranial fossae. In addition, these synchondroses participate differently in cranial base growth prenatally and postnatally, with major differences among species. For example, among primates, the spheno-occipital synchondrosis remains unfused until the end of facial growth in most non-human species (Björk, 1955; Scott, 1958; Melsen, 1969). The midsphenoid synchondrosis fuses prenatally in humans, but remains patent in other primates (Ford, 1958; Scott, 1958; Hofer \& Spatz, 1963; Michejda, 1971, 1972a,b; but see Lager, 1958; Melsen, 1971; Giles et al. 1981). The spheno-ethmoid synchondrosis remains patent in humans during the neural growth period but fuses perinatally in most non-human primates (Scott, 1958; Michejda \& Lamey, 1971).

The goal of this study is to present and test a more complete spatial packing model. We do so with two approaches using mice as an experimental model. The first approach uses correlation statistics to explain variation in CBA from several key variables that derive from alternative spatial packing models. In addition to considering brain volume relative to cranial base length, we consider how the cranial base accommodates variation in facial size, the effects of cranial base widths, and how brain growth above the cranial base and facial growth below the cranial base interact with CBA and are constrained by other dimensions of craniofacial growth. Note that this sort of correlation-based approach does not directly test what epigenetic processes may account for the covariation patterns observed, but does help generate hypotheses that can be further tested. Our second approach, which is more predictive, uses perturbations to craniofacial growth to test hypotheses of integration that relate to CBA. Specifically, we use spatial packing models to test predictions of how specific, known mutations that cause perturbations either to chondrocranial or neural growth influence 


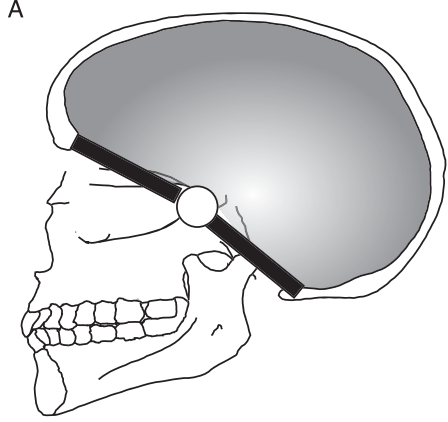

Fig. 2 Models of spatial packing. A simple two-dimensional packing model in which a larger brain in $B$ compared with $A$ is accommodated by a more flexed cranial base. The more complex three-dimensional model, $C$, considers that cranial base in terms of the anterior, middle and posterior cranial fossae (ACF, MCF and PCF), each of which has its own length and width. The brain and neurocranium grow above and laterally from the ACF, MCF and PCF. The face grows inferiorly, anterior and laterally from just the ACF and MCF. See text for further details of the models.
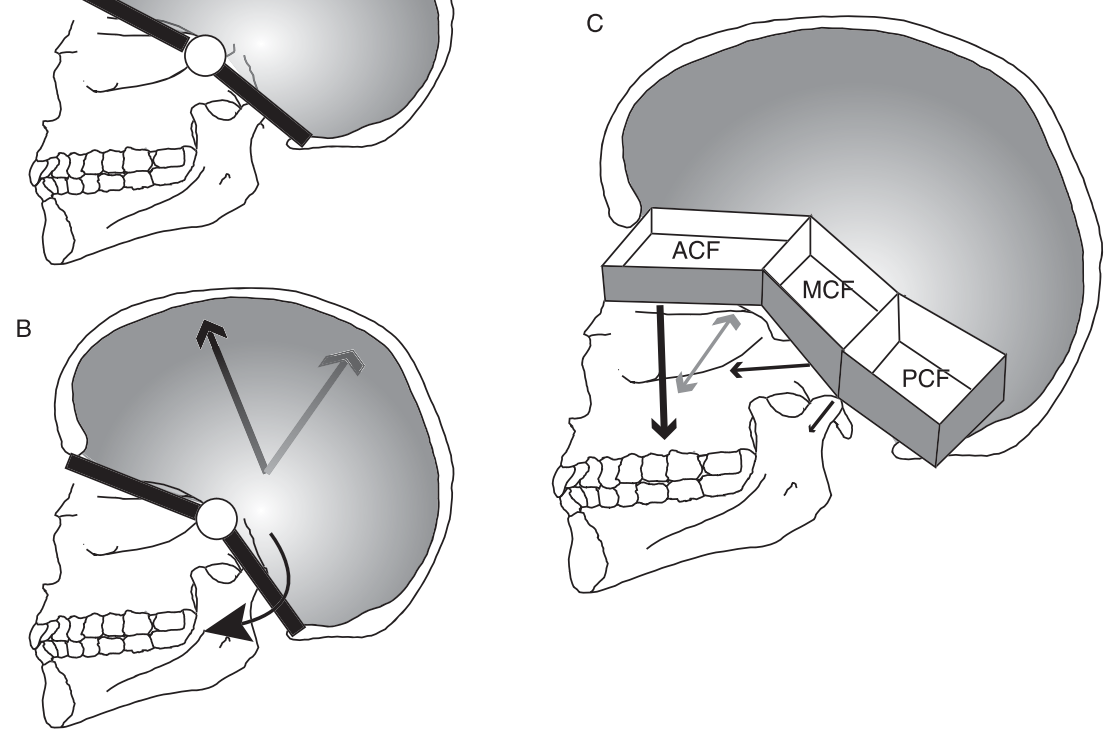

the cranial base angle. Although this approach does not directly assess epigenetic developmental mechanisms, it permits stronger inferences about the developmental bases for observed covariation patterns because the developmental effects of the mutations analysed are known.

\section{Spatial packing models and hypotheses}

Our spatial packing model, illustrated in Fig. 2, expands in several ways on Biegert's original model (Biegert, 1963) and its subsequent formalization by Ross and colleagues (Ross \& Ravosa, 1993; Ross \& Henneberg, 1995; Lieberman et al. 2000b; see also Spoor, 1997; Strait, 1999; McCarthy, 2001).

\section{Model 1: Two-dimensional spatial packing}

There are two ways in which the CBA may participate in spatial packing relative to the length of the cranial base. First, a simple spatial packing model of the brain on the cranial base (see Fig. 2a) predicts that larger brain volume relative to cranial base length (IRE) is accommodated by, and hence correlated with, a more flexed CBA (Hypothesis 1A). As noted above, there is also reason to believe that the cranial base accommodates spatial packing of the face. In particular, because the face grows ventrally from the anterior cranial fossa and forward (anteriorly) from the middle cranial fossa, one can also predict that a longer face relative to the length of the anterior cranial base (the Index of Facial length, IFL) is correlated with a more extended CBA (Hypothesis 1B). Further, the effects of neurocranial and spatial packing should be partially additive. Thus, a greater proportion of variation in CBA should be explained by considering both IRE and IFL (Hypothesis 1C).
Model 2: Three-dimensional spatial packing

One problem with the simple, two-dimensional spatial packing models described above is that they consider only the length and angle of the cranial base but ignore the potential effects of widths. In terms of spatial packing of the brain, it is important to note that the brain grows above the endocranial fossae of the cranial base, each of which is characterized by its own length, width and orientation (see Fig. 2C). It follows that a greater proportion of variance in CBA than explained in Model 1 (Hypothesis $1 A)$ should be accounted for by considering brain size relative to both the width and length of the anterior and posterior portions of the cranial base (Hypothesis 2A). Similar factors also apply to the face, in which one predicts that a greater proportion of variance in $\mathrm{CBA}$ than explained in Model 1 (Hypothesis 1B) should be accounted for by considering facial size relative to both the length and width of the anterior cranial base rather than by considering face size relative to anterior cranial base length alone (Hypothesis 2B). Finally, a greater proportion of variation in $\mathrm{CBA}$ should be explained by considering the combined effects of both three-dimensional facial and neural packing (Hypothesis 2C).

\section{Model 3: Constrained spatial packing}

Finally, the degree to which the face and brain grow relative to the cranial base is also constrained by other aspects of craniofacial shape. In terms of the neurocranium, brain growth may be constrained supero-inferiorly by the falx cerebri, and laterally and posteriorly by other factors (e.g. an overly long posterior cranial fossa may interfere with cantilevering of the skull on the cervical vertebral column). 
Thus in terms of neural packing, considering the length, width and height of the neurocranium should explain more variation in CBA than can be explained by brain size relative to the length and width of the cranial base (Hypothesis 3A). In terms of facial packing, constraints on facial length, width and height should explain more variation in CBA than can be explained by face size relative to anterior cranial base length and width (Hypothesis $3 B$ ). Finally, if variations in CBA are primarily a product of epigenetic interactions among different components of the head during ontogeny, then most of the variation in CBA should be accounted for by the length and width of the components of the cranial base, the length, width and height of the neurocranium, and the length, width and height of the face (Hypothesis 3C). One problem with this hypothesis, however, is that high levels of covariation in the skull may yield spuriously high correlations unrelated to spatial packing. That is, one may explain a high proportion of variance in a single dependent variable (CBA) with a large number of independent variables simply because so many aspects of skull shape are intercorrelated. Thus, a further, related prediction is that the above variables should explain a higher percentage of variation in CBA than in other angles in the skull (Hypothesis 3D). Similarly, a higher proportion of variation in CBA should be explained by the above variables than by other variables (Hypothesis 3E).

\section{Perturbation effects}

A final set of predictions is that mutations which influence brain size, cranial base size or facial growth should influence CBA in predictable ways related to spatial packing. The general prediction is that variation in CBA is primarily a product of interactions among growing regions of the skull rather than intrinsic growth of the synchondroses themselves (contra Scott, 1958). Thus mutations that increase brain size should lead to a more flexed CBA, and mutations that decrease the size of the basicranium relative to brain size should have the same effect. In addition, mutations that increase the size of the face or basicranium should lead to a more extended CBA. These predictions are tested using several mutants from the same genetic background including one that produces increased growth of the brain (mceph), one that produces decreased growth cartilage including the chondrocranium (papps2), and a conditional knockout of the Pten mitosis inhibitor gene which produces overgrowth of cartilage including in the chondrocranium.

\section{Materials and methods}

\section{Experimental design}

The above hypotheses are tested with a mixed comparative and experimental research design using a variety of mouse mutants and wild types that vary considerably in overall craniofacial shape (see below). The comparative approach calculates the proportion of the variance in cranial base angle explained by the three spatial packing models at both the among-individual and the amongstrain levels. The experimental approach focuses on particular mutations that affect the growth of the brain or chondrocranium which the above models hypothesize will result in specific changes in cranial base angle.

Although mice are useful in several ways for testing hypotheses about spatial packing, it is important to keep several limitations and differences in mind. One is that differences among inbred strains of mice are subtle compared to the magnitude of variation that one would find in a broad interspecific sample of primates or other mammals. Another issue is that mouse cranial base anatomy is distinct in two important respects from some mammals, including primates. First, the mouse cranial base is retroflexed, so that the angle between the pre- and postchordal cranial base is greater than $180^{\circ}$ when measured from the ventral aspect (see Fig. 1). Secondly, the spheno-ethmoidal synchondrosis fuses prenatally in mice, and there is no distinct hypophyseal fossa. Thus CBA is measured slightly differently than in primates (as shown in Fig. 1). In spite of these differences, the general principles of craniofacial growth are sufficiently similar for all mammals that the spatial packing hypotheses developed above should apply to mice as well as primates (a hypothesis that we test).

\section{Mouse strains}

For the comparative analysis, we used 458 crania from 19 mouse strains including mutants that vary considerably in craniofacial shape (Table 1). This sample includes both variation of unknown developmental origin as well as variation in known factors such as brain size and chondrocranial growth. To give a sense of withinand between-sample variability in the total mouse sample used here, Fig. 3 plots the first two principal components scores representing $46 \%$ of total sample variance - of the total landmark sample following size correction (see below). Note that whereas some strains have statistically significant mean shape differences, there is considerable overlap in shape among individuals from many different strains.

For the experimental analysis, we focused on three strains with mutations that have known developmental effects on cranial growth and which lead to predictable changes in cranial base angle based on the spatial packing models described above. The first of these strains is Brachymorph (Bm) mutation (C57BL/6J background, the Jackson Laboratory). These mutants have a relatively and absolutely short cranial base because of an autosomal recessive mutation in the phosphoadenosine-phosphosulfate synthetase 2 gene (Papps2) that reduces chondrocranial growth via undersulfation of glycosaminoglycans in cartilage matrix (ul Haque et al. 1998; Kurima et al. 1998). Brachymorph mice thus have a reduction in the size of the chondrocranium relative to the brain, so an increase in relative encephalization. In addition, they have shorter faces than wild types (see Results). We predict, therefore, that the mutation will decrease (flex) the cranial base angle due to both increased encephalization and the shortened face.

The second strain examined has floxed Pten (tumor-suppressor phosphatase with tensin homology) alleles ( 90\% C57BL/6J background, provided by T.W. Mak, Ontario Cancer Institute) crossed with transgenic mice (on a C57BL/6J background) expressing Cre recombinase under control of the Col2a1 gene promoter (Ovchinnikov et al. 2000) (obtained from the Jackson Laboratory). 
Table 1 Mouse strains used

\begin{tabular}{|c|c|c|c|}
\hline Strain & Genotype & $n$ & Craniofacial phenotype \\
\hline$A / J$ & Wild type & 14 & $\begin{array}{l}\text { Elevated frequency of cleft lip and increased susceptibility to clefting } \\
\text { of the secondary palate in response to cortisone treatment (Juriloff, } \\
\text { 1982). }\end{array}$ \\
\hline A/WySnJ & Wild type & 18 & $\begin{array}{l}20 \% \text { frequency of spontaneous cleft lip (Juriloff, 1982). Maxillary } \\
\text { prominence outgrowth is reduced during face formation (Young et al. } \\
\text { 2007; Parsons et al. in press). }\end{array}$ \\
\hline Balb/c & Wild type & 20 & None \\
\hline $\mathrm{C} 3 \mathrm{H}$ & Wild type & 18 & None \\
\hline C57BL/6J & $\operatorname{crf} 4 / \mathrm{crf} 4$ & 16 & $\begin{array}{l}\text { This mutation produces a complex alteration in craniofacial shape } \\
\text { which includes a reduction in the size of the face. }\end{array}$ \\
\hline C57BL/6J & Papps2-IPapps2- & 26 & $\begin{array}{l}\text { A dramatic reduction in the size of the chondrocranium, doming of } \\
\text { the neurocranium and shortening of the face (Hallgrimsson et al. } \\
2006,2007) \text {. }\end{array}$ \\
\hline C57BL/6J & Wild type & 50 & None \\
\hline C57BL/6J*129 & Cre fl/fl & 25 & $\begin{array}{l}\text { Overgrowth of the cartilage including increased posterior basicranial } \\
\text { length and increased facial length. }\end{array}$ \\
\hline C57BL/6J*129 & Pten_Wild type & 20 & None \\
\hline C57BL/6J*Balb6 & Mceph/Mceph & 24 & $\begin{array}{l}\text { Approximately } 25-30 \% \text { increase in the size of the brain by } 90 \text { days of } \\
\text { age (Diez et al. 2003). }\end{array}$ \\
\hline C57BL/6J*Balb6 & Wild type or Heterozygote & 24 & None \\
\hline CBA/J & Wild type & 20 & None \\
\hline DBA/J & Wild type & 20 & None \\
\hline $\mathrm{FVB} / \mathrm{J}$ & Wild type & 20 & None \\
\hline Mceph*Crf4 & Heterozygote, Crf genotype unknown & 35 & There is no obvious craniofacial phenotype. \\
\hline Mceph*Crf4* & Mceph/Mceph, Crf genotype unknown & 40 & There is no obvious craniofacial phenotype. \\
\hline Mixed & Nipbl (+/-) & 23 & Reduction in cranial size and alteration of facial shape. \\
\hline Mixed & Nipbl_Wild type & 40 & None \\
\hline
\end{tabular}

*Five additional individuals with unknown mceph genotype were used in the individual level analysis.

Pten negatively regulates the phosphatidylinositol 3' kinase signaling pathway that is responsible for controlling chondrocyte proliferation and size as well as differentiation and survival (Sansal \& Sellers, 2004). Thus Pten flox/flox $\times$ Col2a1-Cre mice exhibit increased endochondral bone growth and increased chondrocranial size relative to brain size. We predict, therefore, that these mice will have a more extended CBA from both increased face size and decreased encephalization.

Finally, we included homozygous Mceph (megencephaly) mutants (mixed C57BL/6J*Balbc/ByJ background, the Jackson Laboratory). These mice have $25 \%$ expanded but normally shaped brains from generalized neural cell hypertrophy generated by a single recessive autosomal mutation, an 11-bp deletion in the Kcna1 gene (Diez et al. 2003; Petersson et al. 2003). Individuals were genotyped by PCR (primers: TTG TGT CGG TCA TGG TCA TC [forward], GCC CAG GGT AAT GAA ATA AGG [reverse]), and gel bands were sequenced for a subsample due to the small difference between fragment lengths. Because Mceph mice have enlarged brains relative to the cranial base and thus increased encephalization, we therefore predict them to have a more flexed CBA.

\section{Landmarks and measurements}

All crania were micro CT-scanned (Scanco Viva-CT40) at $35 \mu \mathrm{M}$ resolution ( $70 \mathrm{kV}, 160 \mu \mathrm{A}, 500$ projections). In all, 52 three- dimensional landmarks, shown in Fig. 4, were digitized using ANALYZE 3D (http://www.mayo.edu/bir/) with measurement error variances under $1.2 \%$ for interlandmark distances (Hallgrimsson et al. 2006; Hallgrímsson et al. 2004a,b). A subset of these landmarks was used to calculate linear distances, angles, and measures of size (listed in Table 2). Note that CBA in mice cannot be measured as in humans due to the lack of a distinct hypophyseal fossa. Therefore CBA was measured as the ventral aspect angle between a prechordal midsagittal line from the mid-sphenoidal synchondrosis to the foramen caecum, and a postchordal midsagittal line from the mid-sphenoidal synchondrosis to basion (the anterior margin of the foramen magnum). Endocranial volume was calculated from image datasets subjected median (radius $=2$ ) and maximum filtering (radius $=1$ ) in IMAGEJ to remove pseudoforamina and sutures. Virtual endocranial casts were then created in and measured in ANALYZE 3D 5.0 and edited to remove the brain stem and any non-endocranial projections. Measurement error for endocranial volume represents $4.6 \%$ of the total variance or $3.2 \%$ of the mean.

\section{Statistical methods}

The study design consists of individuals nested within groups that are composed of strains and/or genotypes. In the sample, there is variation among groups but also significant variation within 


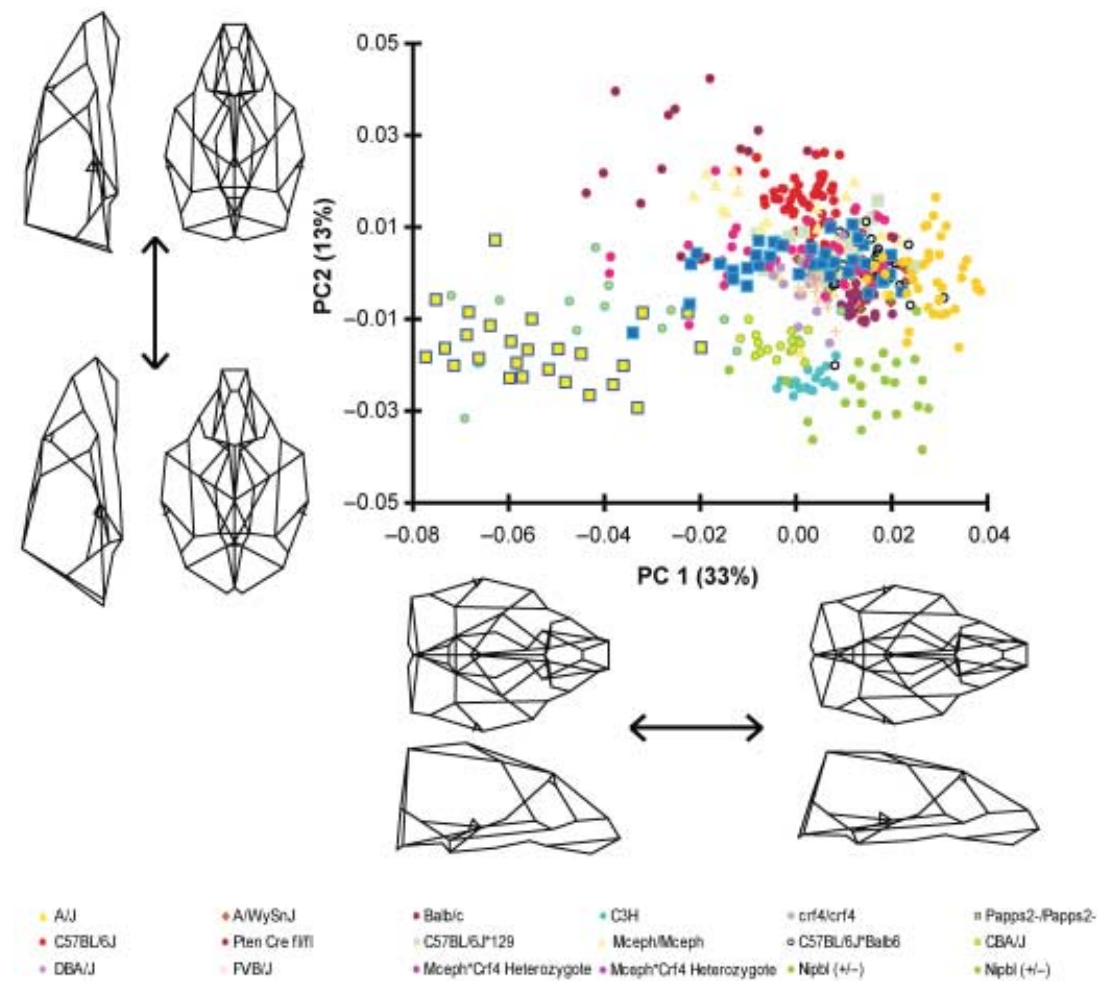

Fig. 3 PCA analysis of variation for PCs 1 and 2 for entire sample (following Procrustes superimposition).

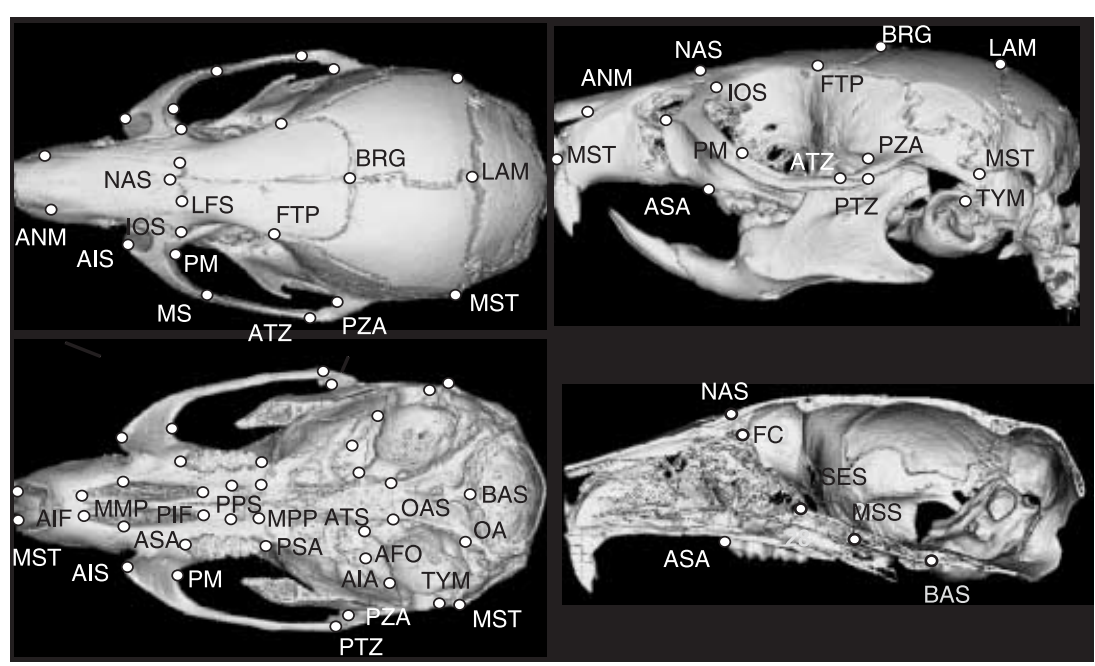

Fig. 4 Landmarks used. For further details on landmarks, see Hallgrimsson et al. (2007). groups. The variation within groups is meaningful because, even within an inbred strain, individual mice vary in the variables hypothesized to explain CBA. Within the mutants, this variation is often elevated (Hallgrimsson et al. 2002, 2006). For this reason, we conducted the analysis at two levels, with the individual as the unit of analysis in one and the mean values for the strain/genotype as the unit for the other.

We used simple linear regressions to determine the strength of the relationship between individual variables and cranial base length. To test the spatial packing hypotheses, we used multiple regression models to determine the total variance explained by the variables specified in the model. Following Freckleton (Freckleton, 2002; Whittingham et al. 2006), we use partial and semi-partial correlations to partition the variance explained by the variables in the spatial packing models.
One statistical challenge to consider is the high level of integration within the skull. Because correlations among measurements, even after size is removed, are so common, one could hypothesize that high proportions of the variance of any craniofacial feature are the consequence of random assortments of highly correlated variables. In other words, the spatial packing model could appear to be confirmed not because it is a good explanation for variation in cranial base angle but simply because all of the variables used to test the model are highly interdependent. To test this possibility, we performed two separate randomization procedures. In the first, we generated 1000 random angles between sets of three landmarks drawn from the set of 52 landmarks used in this study. We then determined how often a multiple regression run with the 12 variables specified in the constrained spatial packing model explained as much or more of the variance of that angle compared 
Table 2 Measurements used. Abbreviations refer to landmarks in Fig. 4

\begin{tabular}{|c|c|}
\hline Variable & Description \\
\hline Cranial base angle & $\begin{array}{l}\text { Midsagittal angle (ventral aspect) between chord from basion (BAS) to the mid-sphenoidal } \\
\text { synchondrosis (MSS), and chord from the foramen caecum (FC) to the mid-sphenoidal synchondrosis } \\
\text { (MSS). }\end{array}$ \\
\hline Posterior basicranial length & Distance from basion (BAS) to the mid-sphenoidal synchondrosis (MSS). \\
\hline Anterior basicranial length & Distance from the mid-sphenoidal synchondrosis (MSS) to foramen caecum (FC). \\
\hline Posterior basicranial width & $\begin{array}{l}\text { Width of the skull at the external auditory meati taken from landmarks on the mid-superior rim of } \\
\text { the tympanic bulla (TYM). }\end{array}$ \\
\hline Anterior basicranial width & $\begin{array}{l}\text { The average of the distances between the foramina ovale (AFO) on each side and a landmark at } \\
\text { the intersection of the frontal suture and the orbital rim on each side (IOS). }\end{array}$ \\
\hline Endocranial volume & The three-dimensional internal volume of the cranial vault (virtual endocast). \\
\hline Neurocranial height & Distance from the mid-sphenoidal synchondrosis (MSS) to lambda (LAM). \\
\hline Neurocranial length & $\begin{array}{l}\text { Distance between lambda (LAM) and the midpoint of a line between a landmark at the junction } \\
\text { between the frontal, parietal and temporal bones (FTP). }\end{array}$ \\
\hline Neurocranial width & $\begin{array}{l}\text { Width of the skull at the occipitomastoid suture (MST). This point, in mice, most frequently } \\
\text { represents the widest point of the neurocranium. }\end{array}$ \\
\hline Facial centroid size & The centroid size of the configuration of all landmarks in the face. \\
\hline Facial length & $\begin{array}{l}\text { The average of two measures of facial length: upper facial length (the distance between the alveolar } \\
\text { rim of the maxillary incisor [MSI] and nasion [NAS]) and palatal length (the distance between the } \\
\text { incisive foramen [AIF] and the posterior alveolar tubercle [PSA]). }\end{array}$ \\
\hline Facial height & $\begin{array}{l}\text { The distance between the midpoint of a line between the posterior alveolar tubercle (PSA) on each } \\
\text { side and foramen caecum (FC). }\end{array}$ \\
\hline \multicolumn{2}{|l|}{ Indices } \\
\hline Index of relative encephalization & $\begin{array}{l}\text { The cube root of endocranial volume divided by basicranial length (anterior }+ \text { posterior basicranial } \\
\text { lengths above). }\end{array}$ \\
\hline Index of facial length & Facial length divided by anterior cranial base length. \\
\hline
\end{tabular}

to cranial base angle. In the second randomization, we performed the opposite test and generated 1000 sets of 12 linear distances obtained from our set of 52 landmarks. We then determined how often the randomly generated sets of distances explained as much or more of the variance for cranial base angle as the 11 variables specified in the constrained spatial packing model.

\section{Results}

\section{Model 1: Two-dimensional spatial packing}

Univariate regressions for cranial base angle against relative encephalization (IRE) and relative facial length (IFL) yield low $(r=-0.28,0.30)$ but significant correlations at the individual level (Fig. 5a,c). At the among-strain level, the correlation between relative facial length and cranial base angle is substantially higher $(r=0.56), P<0.05)$, but the correlation with IRE is not significant $(r=0.19$, $P=$ NS) (Fig. 5b,d). As predicted, the combination of IRE and IFL explain approximately $14 \%$ of the total variance in CBA at the among-individual level $(r=0.38, P<0.001)$, but $34 \%$ of the variation in CBA at the among-strain level ( $r=0.58, P<0.05)$. Moreover, when endocranial volume, anterior cranial base length and posterior cranial base length (all factors in IRE) plus facial length are treated as independent variables rather than ratios, multiple regression reveals that they explain $56 \%(r=0.75$, df $=18, P<0.05)$ of the variation in CBA at the among-strain level (Table 3 ). This correlation is slightly lower at the among-individual level $(r=0.56, \mathrm{df}=457, P<0.001)$. Therefore, as predicted by the simple, two-dimensional spatial packing model (Hypotheses 1A, 1B), both IRE and IFL correlate significantly though not strongly with $C B A$, with relatively larger brains correlated with more flexed cranial bases and relatively larger faces correlated with more extended cranial bases. Moreover, the combined two-dimensional spatial packing model explains a relatively higher proportion of total variation in CBA than IRE or IFL alone (Hypothesis $1 \mathrm{C}$ ).

\section{Model 2: Three-dimensional spatial packing}

This model is similar to the two-dimensional model but also incorporates widths of the posterior and anterior cranial base (in other words, an approximation of the area of the cranial base). In this model, measures of facial and brain size, basicranial length and width are included as separate independent variables in a multiple linear regression. As outlined in Table 4, this model explains $34 \%$ of the variation in CBA at the among individual level ( $r=0.58$, $\mathrm{df}=457, P<0.001)$, and $59 \%$ of the variation in CBA at the among-strain level $(r=0.77, \mathrm{df}=18, P=0.057$ ) (Table 3). Therefore, as predicted by three-dimensional spatial packing, bigger brains relative to the area of the cranial base are correlated with more flexed CBAs (Hypothesis 2A), and bigger faces relative to the area of the anterior cranial base are correlated with more extended (retroflexed) CBAs (Hypothesis 2B). However, these variables together 


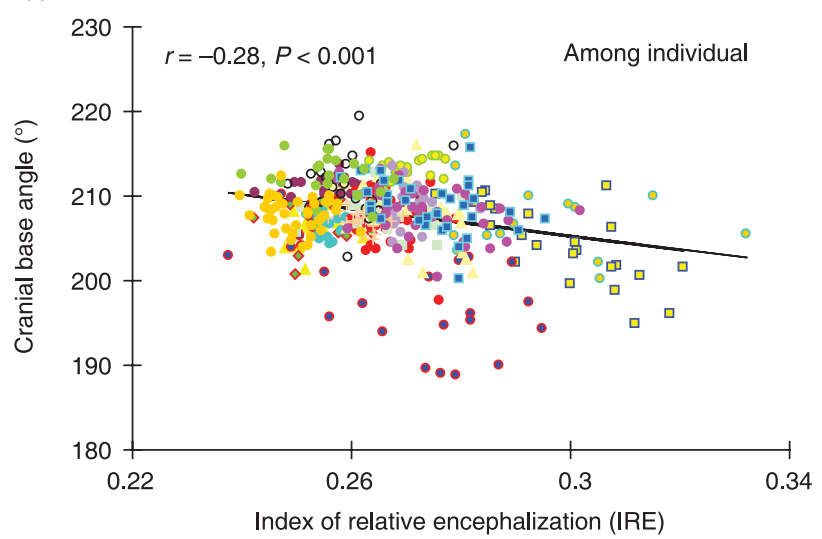

C

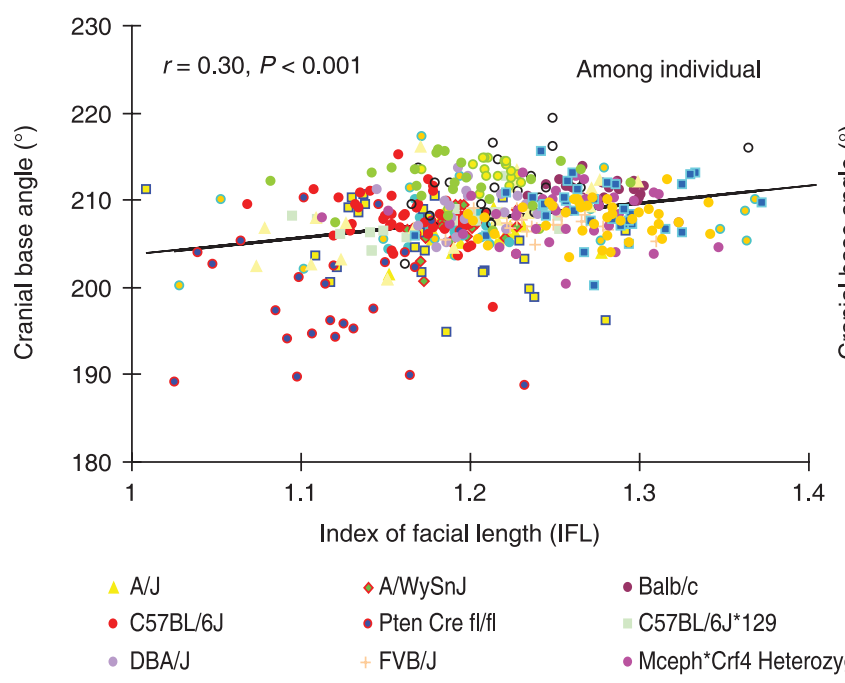

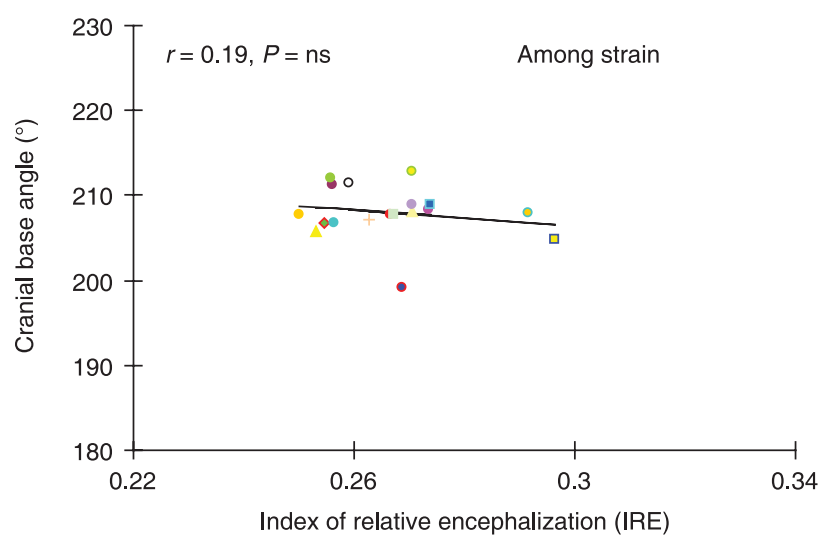

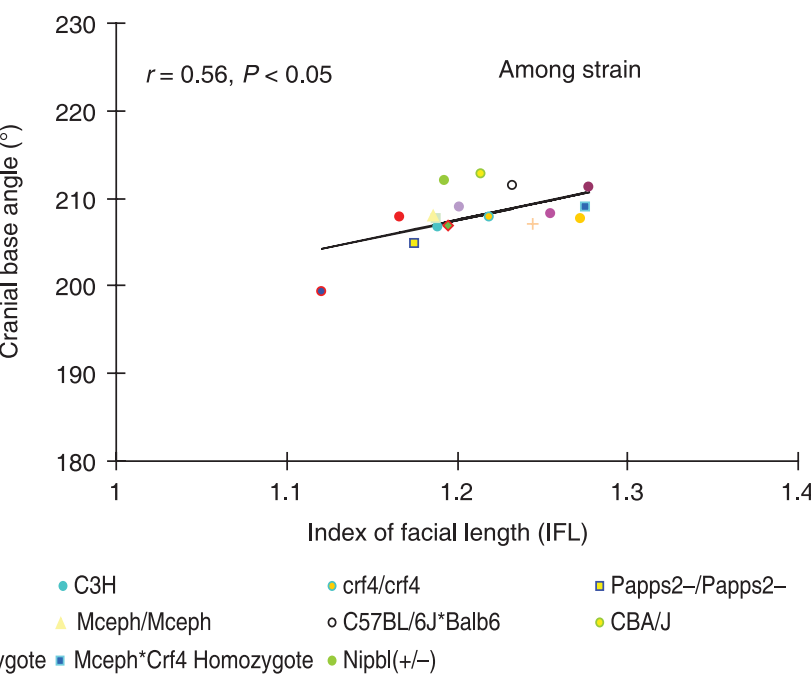

Fig. 5 Regression of basicranial angle (CBA) against the index of relative encephalization (IRE, endocranial volume $\mathrm{e}^{0.33} / \mathrm{crania}$ base length) and the index of relative facial (IFL, face length/anterior cranial base length) at the individual and strain levels.

explain only a little more total variance in CBA than simple two-dimensional spatial packing (Hypothesis 2C).

\section{Model 3: constrained spatial packing}

As predicted, when additional constraints on neural and facial packing are incorporated into the model, then nearly all of the variation in CBA is explained. In the constrained packing model, the height, width and length of both the face and neurocranium are also considered as independent variables in the multiple linear regressions. This full spatial packing model explains $58 \%$ of the variation in CBA at the among-individual level $(r=0.76$, df $=457$, $P<0.0001$ ), and $87 \%$ of the variation in CBA at the among-strain level $(r=0.93, \mathrm{df}=18, P=0.08$ ) (Table 5), a result likely to be statistically significant with more samples. Based on the summed semi-partial correlations, the neurocranial packing (including the posterior basicranium) variables explain $35 \%$ of the variation in CBA at the individual level and $44 \%$ at the among-strain level. Facial packing variables, including the anterior basicranium, explain $8 \%$ of the variation in CBA at the individual level and $16 \%$ at the among-strain level. As with the previous models of spatial packing, bigger brains relative to cranial base area correlate with a more flexed CBA. However, the effect of neurocranial height is particularly marked, individually accounting for $17 \%$ and $22 \%$ of the variance explained at the among-individual and among-strain levels, respectively. The semi-partial and partial correlations for the facial variables reveal that although facial size contributes to variation in CBA, this is to a much lesser degree than neurocranial packing.

We further tested these results against the null hypothesis that the high percentage of variance explained by constrained spatial packing can be accounted for by generally high levels of correlation among many dimensions of the skull. When we compared the percentage of variation of the 12 variables in the model explained in CBA with 1000 randomly generated angles among landmarks, CBA was in the 87th percentile of angles explained. Importantly, 
Table 3 Multiple regression results for the two-dimensional packing model (Model 1)

A. Individual level analysis

\begin{tabular}{|c|c|c|c|c|c|c|c|}
\hline$d f$ & $r$ & $F$ & $P$ & Variable & $r$ & $r_{\mathrm{p}}^{2}$ & $r_{\mathrm{sp}}^{2}$ \\
\hline \multirow[t]{5}{*}{457} & 0.56 & 51 & $<0.001$ & Facial length & -0.01 & 0.00 & 0.00 \\
\hline & & & & Endocranial volume ${ }^{1 / 3}$ & 0.20 & 0.04 & 0.03 \\
\hline & & & & $\begin{array}{l}\text { Posterior basicranial } \\
\text { length }\end{array}$ & -0.29 & 0.19 & 0.16 \\
\hline & & & & $\begin{array}{l}\text { Anterior basicranial } \\
\text { length }\end{array}$ & -0.30 & 0.09 & 0.07 \\
\hline & & & & $\begin{array}{l}\text { Sums of variance } \\
\text { explained }\end{array}$ & & 0.33 & 0.27 \\
\hline
\end{tabular}

B. Strain level analysis

\begin{tabular}{|c|c|c|c|c|c|c|c|}
\hline$d f$ & $r$ & $F$ & $P$ & Variable & $r$ & $r_{\mathrm{p}}^{2}$ & $r_{\mathrm{sp}}^{2}$ \\
\hline \multirow[t]{5}{*}{18} & 0.75 & 4 & $<0.05$ & Facial length & 0.02 & 0.02 & 0.01 \\
\hline & & & & Endocranial volume ${ }^{1 / 3}$ & 0.25 & 0.02 & 0.01 \\
\hline & & & & Posterior basicranial length & 0.48 & 0.39 & 0.28 \\
\hline & & & & Anterior basicranial length & -0.26 & 0.23 & 0.13 \\
\hline & & & & Sums of variance explained & & 0.66 & 0.43 \\
\hline
\end{tabular}

Table 4 Multiple regression results for the three-dimensional packing model (Model 2)

A. Individual level analysis

\begin{tabular}{|c|c|c|c|c|c|c|c|}
\hline$d f$ & $r$ & $F$ & $P$ & Variable & $r$ & $r_{\mathrm{p}}^{2}$ & $r_{\mathrm{sp}}^{2}$ \\
\hline \multirow[t]{7}{*}{457} & 0.58 & 38 & $<0.001$ & Facial size & -0.07 & 0.00 & 0.00 \\
\hline & & & & Endocranial volume ${ }^{1 / 3}$ & -0.20 & 0.00 & 0.00 \\
\hline & & & & $\begin{array}{l}\text { Posterior basicranial } \\
\text { length }\end{array}$ & 0.29 & 0.14 & 0.11 \\
\hline & & & & $\begin{array}{l}\text { Anterior basicranial } \\
\text { length }\end{array}$ & -0.30 & 0.07 & 0.05 \\
\hline & & & & $\begin{array}{l}\text { Posterior basicranial } \\
\text { width }\end{array}$ & -0.34 & 0.03 & 0.02 \\
\hline & & & & $\begin{array}{l}\text { Anterior basicranial } \\
\text { width }\end{array}$ & -0.12 & 0.00 & 0.00 \\
\hline & & & & $\begin{array}{l}\text { Sums of variance } \\
\text { explained }\end{array}$ & & 0.24 & 0.18 \\
\hline
\end{tabular}

B. Strain level analysis

\begin{tabular}{|c|c|c|c|c|c|c|c|}
\hline df & $r$ & $F$ & $P$ & Variable & $r$ & $r_{\mathrm{p}}^{2}$ & $r_{\mathrm{sp}}^{2}$ \\
\hline \multirow[t]{7}{*}{18} & 0.77 & 38 & 0.057 & Facial size & -0.01 & 0.04 & 0.02 \\
\hline & & & & Endocranial volume ${ }^{1 / 3}$ & -0.24 & 0.01 & 0.00 \\
\hline & & & & Posterior basicranial length & 0.26 & 0.13 & 0.06 \\
\hline & & & & Anterior basicranial length & -0.48 & 0.35 & 0.22 \\
\hline & & & & Posterior basicranial width & -0.42 & 0.04 & 0.02 \\
\hline & & & & Anterior basicranial width & -0.26 & 0.05 & 0.02 \\
\hline & & & & Sums of variance explained & & 0.61 & 0.34 \\
\hline
\end{tabular}

angles with higher correlations were mostly in the basicranium and were related in some way to flexion of the cranial base (Fig. 6). Many centre on basicranial landmarks, connecting to landmarks in the face and neurocranium.
Table 5 Multiple regression results for the constrained packing model (Model 3)

A. Individual level analysis

\begin{tabular}{|c|c|c|c|c|c|c|c|}
\hline df & $r$ & $F$ & $P$ & Variable & $r$ & $r_{\mathrm{p}}^{2}$ & $r_{\mathrm{sp}}^{2}$ \\
\hline \multirow[t]{13}{*}{457} & 0.76 & 52 & $<0.001$ & Facial size & 0.07 & 0.00 & 0.00 \\
\hline & & & & Endocranial volume $e^{1 / 3}$ & 0.20 & 0.07 & 0.03 \\
\hline & & & & $\begin{array}{l}\text { Posterior basicranial } \\
\text { length }\end{array}$ & -0.29 & 0.02 & 0.01 \\
\hline & & & & $\begin{array}{l}\text { Anterior basicranial } \\
\text { length }\end{array}$ & 0.30 & 0.07 & 0.03 \\
\hline & & & & $\begin{array}{l}\text { Posterior basicranial } \\
\text { width }\end{array}$ & 0.34 & 0.01 & 0.01 \\
\hline & & & & $\begin{array}{l}\text { Anterior basicranial } \\
\text { width }\end{array}$ & 0.12 & 0.00 & 0.00 \\
\hline & & & & Neurocranial width & 0.38 & 0.03 & 0.01 \\
\hline & & & & Facial width & 0.17 & 0.00 & 0.00 \\
\hline & & & & Facial height & 0.20 & 0.10 & 0.04 \\
\hline & & & & Neurocranial height & -0.06 & 0.28 & 0.17 \\
\hline & & & & Facial length & -0.01 & 0.00 & 0.00 \\
\hline & & & & Neurocranial length & 0.44 & 0.23 & 0.13 \\
\hline & & & & $\begin{array}{l}\text { Sums of variance } \\
\text { explained }\end{array}$ & & 0.82 & 0.43 \\
\hline
\end{tabular}

B. Strain level analysis

\begin{tabular}{|c|c|c|c|c|c|c|c|}
\hline df & $r$ & $F$ & $P$ & Variable & $r$ & $r_{\mathrm{p}}^{2}$ & $r_{\mathrm{sp}}^{2}$ \\
\hline \multirow[t]{13}{*}{18} & 0.93 & 3.3 & 0.08 & Facial size & -0.15 & 0.18 & 0.03 \\
\hline & & & & Endocranial volume ${ }^{1 / 3}$ & -0.24 & 0.28 & 0.05 \\
\hline & & & & Posterior basicranial length & 0.26 & 0.21 & 0.04 \\
\hline & & & & Anterior basicranial length & -0.48 & 0.18 & 0.03 \\
\hline & & & & Posterior basicranial width & -0.42 & 0.18 & 0.03 \\
\hline & & & & Anterior basicranial width & -0.26 & 0.02 & 0.00 \\
\hline & & & & Neurocranial width & -0.45 & 0.29 & 0.05 \\
\hline & & & & Facial width & -0.21 & 0.06 & 0.01 \\
\hline & & & & Facial height & -0.34 & 0.41 & 0.09 \\
\hline & & & & Neurocranial height & -0.03 & 0.62 & 0.22 \\
\hline & & & & Facial length & -0.01 & 0.01 & 0.00 \\
\hline & & & & Neurocranial length & -0.51 & 0.31 & 0.06 \\
\hline & & & & Sums of variance explained & & 2.75 & 0.61 \\
\hline
\end{tabular}

These angles would be directly impacted by variation in the cranial base angle as well as variation in neurocranial height and length. Others relate to the width and degree of the anterior basicranium. We also compared the percentage of CBA variation accounted for by the 12 variables in the constrained spatial packing model with 1000 random sets of 12 interlandmark distances. In this simulation, the 12 variables specified in the constrained packing model were in the 96th percentile of randomly generated variable sets. Measurements that occurred multiple times in the randomly generated sets that correlated highly with cranial base angle are likely related to important determinants of cranial base angle. Figure 6 shows the randomly generated variables that occurred more than twice in the sets that explained more variance in cranial base angle than the constrained spatial packing model. Within this set, the 


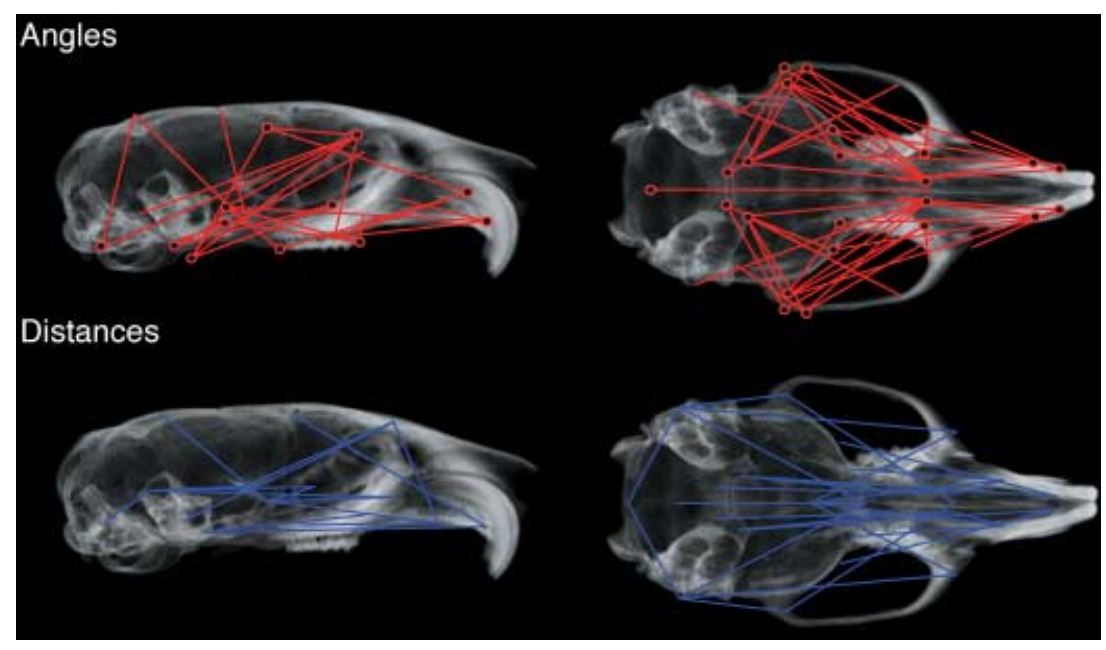

Fig. 6 Results of randomization analyses. Top, angles with higher correlation to CBA generated by 1000 randomized angles within sample. Note that almost all these angles are cranial base. Bottom, random sets of 12 interlandmark distances that explain a higher percentage of CBA in the constrained spatial packing model Note that most of these distances relate to the length of the cranial base.
A

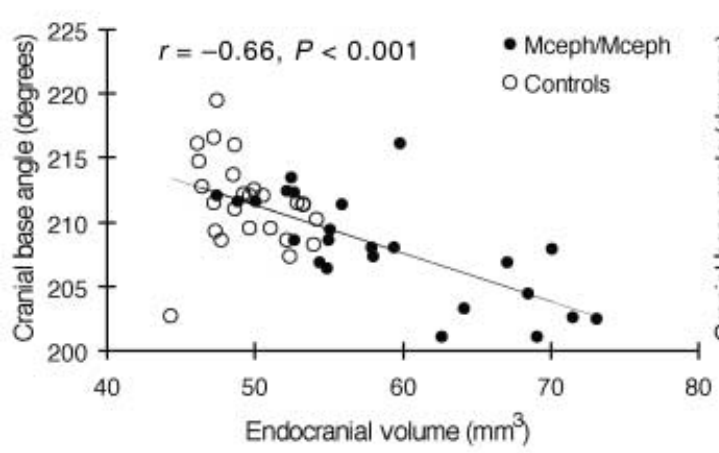

B

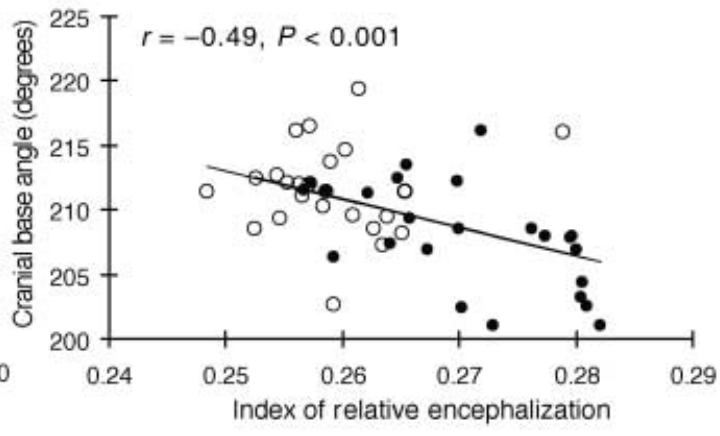

IRE

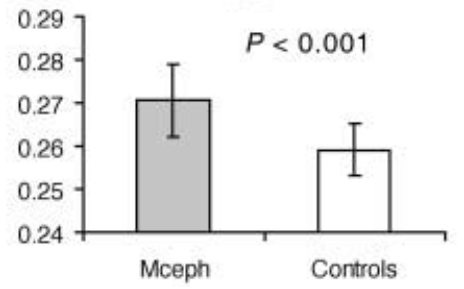

CBA (degrees)

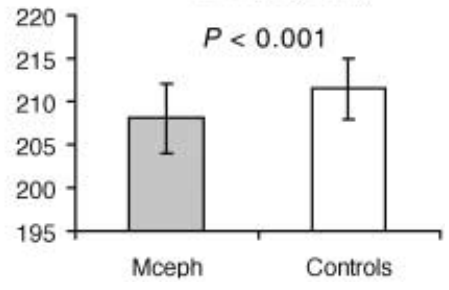

Fig. 7 Analyses of Mceph (more encephalized) mutants vs. wild types. A, CBA vs. IRE; B, CBA vs. IFL; C, comparison of means.

distance between the mid-sphenoidal and sphenoethmoidal synchondroses, a component of anterior basicranial length, occurred most often (seven times).

\section{Perturbation effects}

A final set of analyses tested the predicted effects of three particular mutations on CBA. The first mutation we examined was mceph, which generates a larger brain. The effects of this mutation in CBA and craniofacial shape are illustrated in Fig. 7. As predicted, an ANOvA comparison of endocranial volume, IRE and CBA confirmed the prediction that the mceph/mceph mutants would have a significantly more flexed CBA $(F=9.9, \mathrm{df}=47, P<0.1)$ along with increased endocranial volume $(F=33, \mathrm{df}=47, P<0.001)$ and IRE $(F=27, \mathrm{df}=47, P<0.001)$. Linear regressions of the pooled mutant and wild-type samples reveal a significant correlation between CBA and both endocranial volume and IRE in this sample.

The second mutation we examined was brachymorph $(B M)$. As Fig. 8 indicates, this mutation leads to a significantly smaller cranial base (ANOVA $F=102, \mathrm{df}=56, P<0.001$ ) without affecting endocranial volume (ANOVA $F=1.8$, df $=56$, $P=0.18$ ), thus increasing IRE (ANOVA: $F=114$, $\mathrm{df}=56$, $P<0.001)$. As predicted, CBA is significantly more flexed in these mutants than in wild-type controls (ANOvA $F=11$, $\mathrm{df}=56, P<0.01$ ), and a linear regression for the pooled mutant and wild-type control sample reveals that cranial 

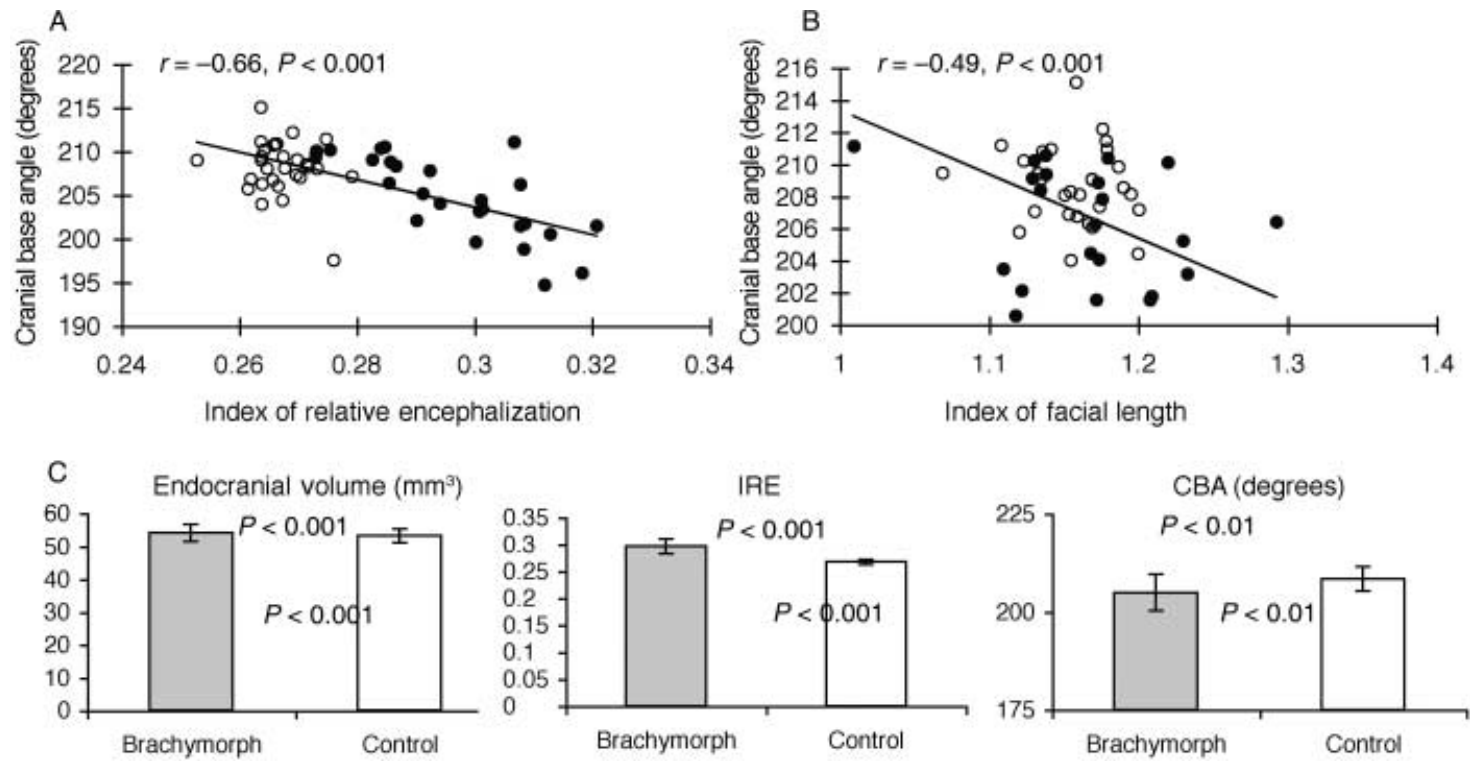

Fig. 8 Analyses of brachymorph (shorter cranial bases) mutants versus wild types. A, CBA vs. IRE; B, CBA vs. IFL; C, comparison of means.

A Cranial base angle against IRE

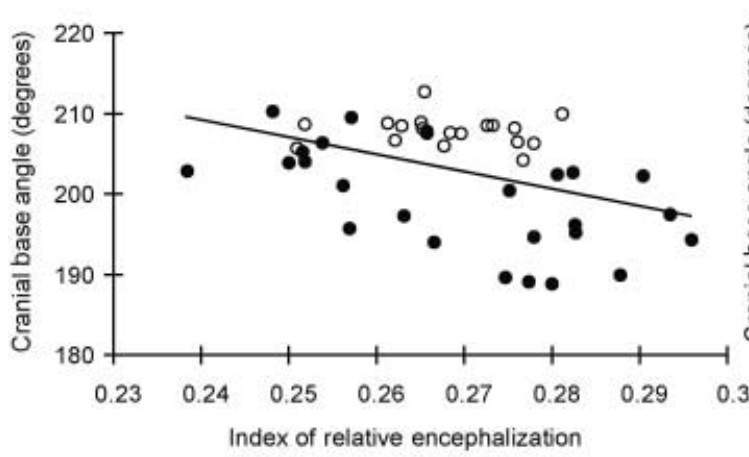

C Comparisons of means

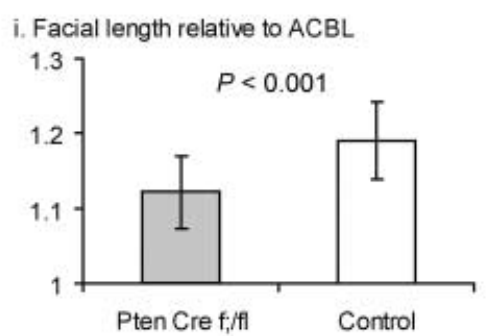

B Cranial base angle against facial length relative to ACBL
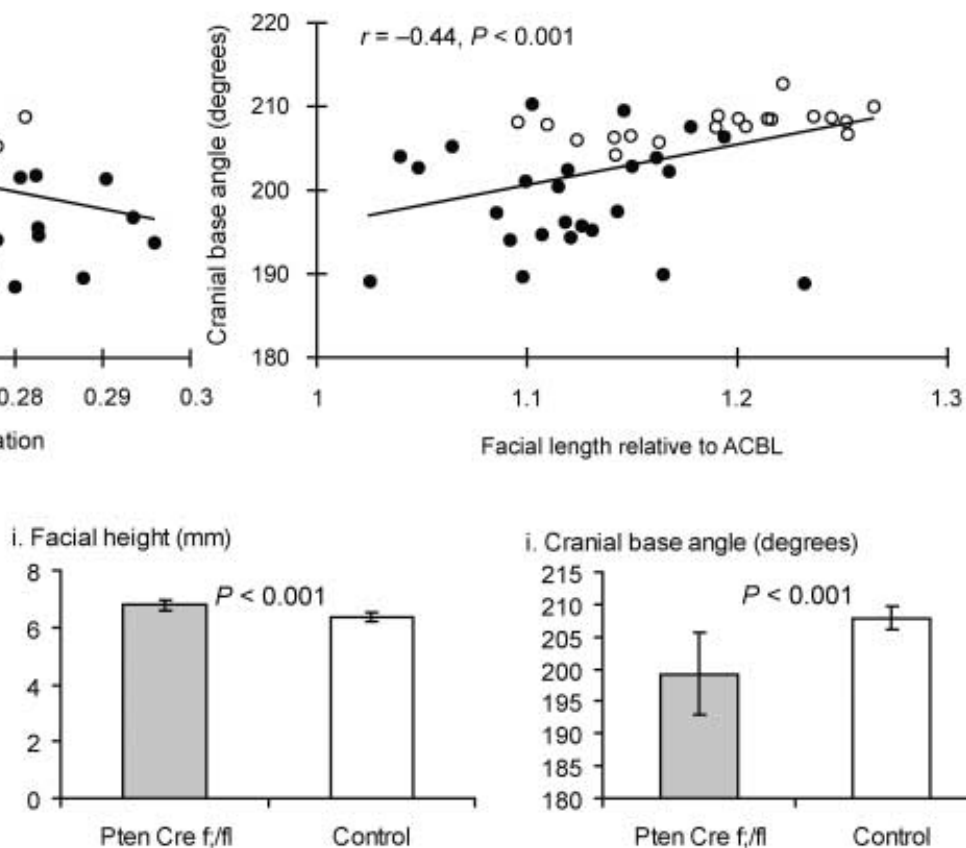

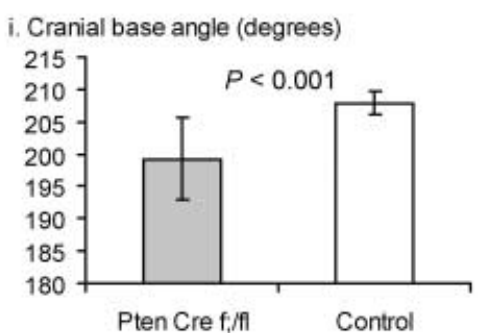

Fig. 9 Analyses of pten mutants (longer anterior and shorter posterior cranial base lengths) vs. wild types. A, CBA vs. IRE; B, CBA vs. IFL; C, comparison of means.

base angle varies significantly with IRE in this sample. It is interesting to note that face length (ANOVA: $F=3, d f=56$, $P=0.08$ ) and anterior cranial base length (ANOVA: $F=12$, $\mathrm{df}=56, P<0.01)$ are both reduced in the brachymorph mutants. As a result, facial length relative to anterior cranial base length is not altered. However, the variance of facial length relative to anterior cranial base length is increased in the brachymorph mutants (Levene's test: $\mathrm{df}=56, F=7, P<0.05)$. In the pooled sample, this variation in relative facial length is significantly correlated with cranial base angle $(r=0.44, \mathrm{df}=56, P<0.001)$, although the means do not differ between the genotypes (Fig. 8b).

The third mutation we examined, Pten, leads to a significantly longer (9.2\%) anterior cranial base length $(F=49, \mathrm{df}=43, P<0.001)$ as well as a shorter $(8.4 \%)$ posterior cranial base $(F=13, \mathrm{df}=43, P<0.01)$. As shown in Fig. 9, although the face in the Pten mutants is significantly longer than in wild types $(F=5, \mathrm{df}=43, P<0.05)$, 
the net effect is to reduce facial length relative to anterior cranial base length $(F=20, \mathrm{df}=43, P<0.001)$ by about $6 \%$. IRE is not significantly different in mutants and controls, presumably because of the offsetting effects of the mutation on anterior and posterior cranial base. Regardless, as predicted from the reduction in face length relative to anterior cranial base length, $C B A$ is significantly more flexed $(F=32, \mathrm{df}=43, P<0.001)$. Within the pooled sample, face length relative to anterior cranial base length is significantly correlated with cranial base angle (Fig. 9a). Although mean IRE is not affected, the mutants have increased variance in the basicranial length (Levene's test: $F=10, \mathrm{df}=43, P<0.01$ ) and IRE (Levene's test: $F=15.8$, $\mathrm{df}=43, P<0.001$ ) leading to a significant correlation between IRE and CBA in the pooled sample (Fig. 9b).

\section{Discussion}

The results presented here provide broad support for the general hypothesis that variation in CBA reflects the influences of both neural and spatial packing. The first of the three models, the simple two-dimensional packing hypothesis, is supported by evidence that larger brain volume relative to cranial base length is significantly correlated with a more flexed CBA, and that larger face size relative to anterior cranial base length is significantly correlated with a more extended CBA (Hypotheses 1A and 1B). Together, facial and neural packing account for $14 \%$ and $34 \%$ of the total variation in CBA at the amongindividual and among-strain levels, respectively (Hypothesis 1C). Given the low degree of variation within mouse strains, one expects less significant and/or weaker correlations at the among-individual level. As predicted, the threedimensional spatial packing model (Model 2) explains slightly more variation than the two-dimensional model, indicating that widths of the cranial base affect the degree to which the cranial base can accommodate relatively larger brains (Hypothesis 2A) and faces (Hypothesis 2B). In addition, considering three-dimensional neural and facial packing together accounts for $34 \%$ and $59 \%$ of the total variation in CBA at the among-individual and amongstrain levels, respectively (Hypothesis 2C). And when spatial packing is considered more broadly in terms of constraints on how the face and brain can grow relative to the cranial base (model 3), then almost all the variation in CBA within the sample can be explained, particularly at the among-strain level (87\%). Randomization analyses, moreover, confirm that these correlations are unlikely to be the result of chance, despite widespread, high levels of correlation and covariation in the skull. It is further noteworthy to observe that mice with relatively larger brains, small cranial bases (narrow and short) and vertical braincases have more flexed cranial bases. Likewise, mice with large faces that are long relative to anterior cranial base length and width have more extended cranial bases.
Tests of Models 1-3, therefore, all support spatial packing hypotheses that the angle of the cranial base helps the cranium to accommodate the volume of the brain above the cranial base and the face below and in front of the cranial base. Although spatial packing has been mostly been considered in relation to primates - in which there is considerable variation in brain size as well as face size - it is noteworthy that the model also applies to a far more restricted and much less varied sample of mouse strains. As one would expect given substantially less variation, the proportion of among-strain variation in CBA explained by IRE (Model 1) is much lower in the mouse sample $\left(r^{2}=0.08\right)$ than across primates $\left(r^{2}=0.42\right)$ (Ross \& Ravosa, 1993; Lieberman et al. 2000b). An additional factor is that encephalization in mice, even the mceph mutants, is quite low compared with primates, whereas relative facial length is particularly pronounced. Further, the amount of variation in encephalization among mouse strains is very low compared with interspecific variation in primates. This may also explain why endocranial volume itself contributes only minimally to variation in cranial base angle in the comparative sample (Tables 3 and 4), whereas mutations that influence endocranial volume relative to basicranial length clearly affect CBA. These differences between mice and primates probably help account for the finding that IFL contributes more substantially than IRE to CBA variation in mice in the two-dimensional analysis. Importantly, total among-strain variation in CBA that can be explained by simple models of spatial packing (Models 1 and 2) is high, between $34 \%$ and $59 \%$. Although there have been several indications that face size, especially length, also contributes to CBA variation in primates (Ross \& Ravosa, 1993; Lieberman \& McCarthy, 1999; Jeffery \& Spoor, 2002), these results suggest that the combination of relative brain size and face size also accounts for a larger percentage of CBA variation in primates than IRE alone (currently under study).

The evidence that variation in CBA helps accommodate spatial packing of the brain above the cranial base and the face below the cranial base needs to be further tested in primates but, if correct, this has particularly interesting implications for human evolution. There has been a dramatic increase in brain size combined with a decrease in facial length over the course of human evolution. These changes, however, did not occur in concert or in a simple way. Although Australopithecus species from the Pliocene tend to have slightly larger endocranial volumes than chimpanzees and the earliest hominins (e.g. Sahelanthropus tchadensis), they vary considerably in facial size and, especially facial length. Consequently, whereas CBA in very prognathic species such as Australopithecus afarensis may be equivalent to CBA in chimpanzees, more orthognathic species such as Australopithecus boisei appear to have more flexed CBAs (Spoor, 1997), possibly because less cranial base extension occurred to accommodate a 
shorter face. Another interesting contrast is between Homo sapiens and archaic species of Homo such as Homo neanderthalensis. Both species have nearly equivalent brain sizes (endocranial volume actually tends to be slightly larger in Neanderthals), but CBA in modern humans appears to be approximately $15^{\circ}$ more flexed, perhaps because of a shorter face (Lieberman, 1998, 2000; Spoor et al. 1999; Lieberman et al. 2002, 2004). Shorter faces and more flexed cranial bases also correspond to other shifts in modern human craniofacial shape such as a shorter pharynx because of integration between the cranial base and face (Lieberman et al. 2000b; McCarthy \& Lieberman, 2001).

Another implication of the spatial packing model presented and tested here is the role of epigenetic interactions between the cranial base and both the face and brain in influencing overall cranial shape. It has long been appreciated that the head is a highly integrated structure that derives its shape and size from numerous interactions among many regions of skull (the face, basicranium and neurocranium), which in turn encapsulate and/or provide attachment sites for many organs and spaces such as the brain, eyes, muscles of mastication, pharynx, teeth, and so on (for reviews, see Moss, 1997a,b; Enlow, 1990). How the skull is able to accommodate growth in the shape and size of these many units during ontogeny without impeding function is a key problem. The results presented here provide strong support for the hypothesis that the cranial base plays a central role in this complex set of accommodation processes. Although there may be some intrinsic growth potential of the cranial base, variation in CBA among mice indicates that many factors contribute collectively although unequally to either flexion or extension of the cranial base. Most importantly, as the brain grows above the three endocranial fossae, the cranial base flexes, apparently to accommodate a bigger brain relative to the length and width of these basicranial components. Additionally, as the face grows below the anterior cranial fossa and forward from the middle cranial fossa, the cranial base extends, apparently to accommodate variations in facial length relative to the length and width of the anterior cranial base. Because the degree to which the brain and face grow relative to the cranial base is constrained by other factors (e.g. the widths of the endocranial fossae, face and neurocranium, along with the height of the neurocranium), only a few variables are necessary to explain a strikingly high percentage of CBA variation (87\% at the among-strain level). In other words, variation in CBA appears to be highly epigenetic to help accommodate growth among many different parts of the head. This high degree of epigenetic interaction may explain why the cranial base angle is so variable and reversible in both ontogeny and during evolution. For example, the human cranial base first flexes and then extends during prenatal ontogeny, and then flexes again postnatally (Lieberman \& McCarthy,
1999; Jeffery \& Spoor, 2002, 2004). In addition, CBA is relatively extended in chimpanzees, early australopiths, and Neanderthals, but more flexed in modern humans and robust australopiths, perhaps because of varying combinations of brain volume and facial length.

More research is necessary to test in greater detail the hypothesis that the cranial base, especially CBA, is highly epigenetically responsive to certain stimuli to accommodate spatial packing of both the brain and face. Indeed, the overall results, including the randomization tests, show that variation in cranial base angle is part of a complex of shape variation in the basicranium that correlates with particular complexes of shape variation elsewhere in the skull. It follows that focusing so much on the angle of the cranial base may lead us to overlook other important aspects of cranial base anatomy that influence overall craniofacial shape. That said, the results presented above do reinforce those of previous studies that indicate that CBA variation does play a key role in accommodating variations in neural and facial form. One useful test of the model (currently ongoing) is to examine variation across primates more comprehensively in three dimensions using data on both the brain and the face. It would also be useful to know more about the mechanisms by which cranial base actually flexes and extends in response to brain and facial growth. As noted above, we do not know to what extent the cranial base flexes through differential growth within particular synchondroses and/or through drift of the particular regions of the cranial base (e.g. the basioccipital clivus). Further information is also needed on the pathways by which mechanical forces may influence these shifts. One likely hypothesis is that the cranial base may respond to neural or facial growth via the Fgf2 pathway, as is the case for the neurocranium (Yu et al. 1997; Opperman, 2000; Morriss-Kay \& Wilkie, 2005).

Regardless of the precise epigenetic mechanisms by which the cranial base grows to accommodate and/or constrain overall craniofacial shape, it is important to keep in mind that we should expect the system to be highly variable in certain predictable ways. There are probably just a few mechanisms that cause different parts of cranial base to flex or extend, and there are maybe a dozen or so different factors of facial and neurocranial growth that may influence these processes. For example, in the case of the mice analysed here, the cranial base may flex because of a larger brain, a shorter or narrower cranial base, or a shorter face. We do not know to what extent these variables influence the same processes that lead to more flexion (or less extension), but such constrained variability may be a critical aspect of how complex integrated structures such as heads grow. Morphological variability is produced at many hierarchical levels of development, beginning with genetic mutations that influence the development of particular units of the head (e.g. rates of brain cell mitosis, chondrocyte proliferation, or collagen synthesis 
by osteoblasts), but also at higher levels such as the factors that regulate epigenetic interactions among cells. As we have previously argued (Hallgrimsson et al. 2007), these epigenetic processes and how they structure and generate phenotypic variation in complex structures are ontologically as important as the many developmental pathways that lead to the morphogenesis of the many components of the head. Thus a better understanding of how the cranial base functions in this regard may lead to significant insights into the development and evolution of the head.

\section{Acknowledgements}

We thank Chris Cannon for advice related to genotyping. We are grateful for funding provided by American School of Prehistoric Research (D.E.L.), National Science and Engineering grant 23899206, Canadian Foundation for Innovation grant \#3923, Alberta Innovation and Science grant \#URSI-01-103-RI, Canadian Institutes of Health Research grant \#131625, Genome Canada and Genome Alberta grant to (B.H.).

\section{References}

Bastir M, Rosas A (2006) Correlated variation between the lateral basicranium and the face: a geometric morphometric study in different human groups. Arch Oral Biol 51, 814-824.

Bastir M, Rosas A, O'Higgins, P (2006) Craniofacial levels and the morphological maturation of the human skull. J Anat 209, 637654.

de Beer GR (1937) The Development of the Vertebrate Skull. Oxford: Oxford University Press.

Biegert J (1957) Der Formandel des Primateschïndels und seine Beziehungen zur ontogeneteschen Entwickling und den phylogenetischen Spezialisationen der Kopforgane. Morph Jahrb 98, 77-199.

Biegert J (1963) The evaluation of characters of the skull, hands and feet for primate taxonomy. In Classification and Human Evolution (ed. Washburn SL), pp. 116-145. Chicago: Aldine de Gruyter.

Björk A (1955) Cranial base development. Am J Orthod 41, 198225.

Bolk $L$ (1910) On the slope of the foramen magnum in primates. Kon Akad Wet Amst 12, 525-534.

Cheverud JM (1982) Phenotypic, genetic, and environmental integration in the cranium Evolution 36, 499-516.

Cheverud JM (1996) Developmental integration and the evolution of pleiotropy. Am Zool 36, 44-50.

Dabelow A (1929) Über Korrelationen in der phylogenetischen Entwicklung der Schädelform. I. Morph Jahrb 63, 1-49.

Diez M, Schweinhardt P, Petersson S, et al. (2003) MRI and in situ hybridization reveal early disturbances in brain size and gene expression in the megencephalic (mceph/mceph) mouse. Eur $J$ Neurosci 18, 3218-3230.

DuBrul EL, Laskin DM (1961) Preadaptive potentialities of the mammalian skull: an experiment in growth and form. Am J Anat 109, 117-132.

Enlow DH (1990) Facial Growth, 3rd edn. Philadelphia: Saunders.

Enlow DH, Azuma M (1975) Functional growth boundaries in the human and mammalian face. In Morphogenesis and Malformation of Face and Brain (ed. Bergsma D), pp. 217-230. New York: Alan R. Liss.
Ford EHR (1958) Growth of the human cranial base. Am J Orthodont 44, 498-506.

Freckleton RP (2002) On the misuse of residuals in ecology: regression of residuals versus multiple regression. J Anim Ecol 71, 542-545.

Giles WB, Philips CL, Joondeph DR (1981) Growth in the basicranial synchondroses of adolescent Macaca macaca. Anat Rec 199, 259-266.

Gould SJ (1977) Ontogeny and Phylogeny. Cambridge: Belknap Press.

Hallgrimsson B, Willmore K, Hall BK (2002) Canalization, developmental stability, and morphological integration in primate limbs. Yearb Phys Anthropol 45, 131-158.

Hallgrimsson B, Dorval CJ, Zelditch ML, German RZ (2004a) Craniofacial variability and morphological integration in mice susceptible to cleft lip and palate. J Anat 205, 501-517.

Hallgrimsson B, Willmore K, Dorval C, Cooper DM (2004b) Craniofacial variability and modularity in macaques and mice. $J$ Exp Zoolog B Mol Dev Evol 302, 207-225.

Hallgrimsson B, Brown JJY, Ford-Hutchinson AF, Sheets HD, Zelditch ML, Jirik FR (2006) The brachymorph mouse and the developmental-genetic basis for canalization and morphological integration. Evol Dev 8, 61-73.

Hallgrimsson B, Lieberman DE, Liu W, Ford-Hutchinson AF, Jirik FR (2007) Epigenetic interactions and the structure of phenotypic variation in the cranium. Evol Dev 9, 76-91.

ul Haque MF, King LM, Krakow D, et al. (1998) Mutations in orthologous genes in human spondyloepimetaphyseal dysplasia and the brachymorphic mouse. Nat Genet 20, 157-162.

Hofer H (1960) Studien zum Problem des Gestaltwandels des Schädels der Säugetiere, insbesondere der Primaten. I. Die medianen Kruemmundgen des Schädels und ihr Ehrfassung nach Landzert. Z Morph Anthropol 50, 299-316.

Hofer $\mathbf{H}$ (1969) On the evolution of the craniocerebral topography in primates. Ann N Y Acad Sci 162, 341-356.

Hofer H, Spatz W (1963) Studien zum Problem des Gestaltwandels des Schädels der Säugetiere, insbesondere der Primaten. II. Über die kyphosen Fetaler und neonater Primatenschädel. Z Morphol Anthropol 53, 29-52.

Jeffery N (2003) Brain expansion and comparative prenatal ontogeny of the non-hominoid primate cranial base. J Hum Evol 45, 263284.

Jeffery N, Spoor F (2002) Brain size and the human cranial base: a prenatal perspective. Am J Phys Anthropol 118, 324-340.

Jeffery N, Spoor F (2004) Ossification and midline shape changes of the human fetal cranial base. Am J Phys Anthropol 204, 7192.

Juriloff DM (1982) Differences in frequency of cleft lip among the A strains of mice. Teratology 25, 361-368.

Kurima K, Warman ML, Krishnan S, et al. (1998) A member of a family of sulfate-activating enzymes causes murine brachymorphism. Proc Natl Acad Sci U S A 95, 8681-8685.

Lager $\mathbf{H}$ (1958) A histological description of the cranial base in Macaca rhesus. Trans Eur Odont Soc 34, 147-156.

Laitman JT, Crelin ES (1976) Postnatal development of the basicranium and vocal tract region in man. In Symposium on the Development of the Basicranium (ed. Bosma JF), pp. 206-219. Washington, D.C.: U.S. Government Printing Office.

Lieberman DE (1998) Sphenoid shortening and the evolution of modern human cranial shape. Nature 393, 158-162.

Lieberman DE (2000) Ontogeny, homology, and phylogeny in the Hominid craniofacial skeleton: the problem of the browridge. In Development, Growth and Evolution (eds O'Higgins P, Cohn M), pp. 85-122. London: Academic Press. 
Lieberman DE, McCarthy RC (1999) The ontogeny of cranial base angulation in humans and chimpanzees and its implications for reconstructing pharyngeal dimensions. J Hum Evol 36, 487517.

Lieberman DE, Mowbray K, Pearson, OM (2000a) Basicranial influences on overall cranial shape. J Hum Evol 38, 291-315.

Lieberman DE, Ross CF, Ravosa MJ (2000b) The primate cranial base: ontogeny, function and integration. Yearb Phys Anthropol 43, 117-169.

Lieberman DE, McBratney BM, Krovitz G (2002) The evolution and development of cranial form in Homo sapiens. Proc Natl Acad Sci U S A 99, 1134-1139.

Lieberman DE, Krovitz GE, McBratney-Owen B (2004) Testing hypotheses about tinkering in the fossil record: the case of the human skull. J Exp Zool (Mol Dev Evol) 302B: 284-301.

McCarthy RC (2001) Anthropoid cranial base architecture and scaling relationships. J Hum Evol 40, 41-66.

McCarthy RC, Lieberman DE (2001) The Posterior Maxillary (PM) plane and anterior cranial architecture in primates. Anat Rec 264, 247-260.

Melsen B (1969) Time of closure of the spheno-occipital synchondrosis determined on dry skulls. A radiographic craniometric study. Acta Odontol Scand 27, 73-90.

Melsen B (1971) The postnatal growth of the cranial base in Macaca rhesus analyzed by the implant method. Tandlaegebladet 75, 1320-1329.

Michejda M (1971) Ontogenetic changes of the cranial base in Macaca mulatta. Proceeding of the Third International Congress of Primatology, Vol. 1, pp. 215-225, Zurich.

Michejda M (1972a) The role of basicranial synchondroses in flexure processes and ontogenetic development of the skull base. Am J Phys Anthropol 37, 143-150.

Michejda M (1972b) Significance of basicranial synchondroses in nonhuman primates and man. Proceeding of the Third Conference on Experimental Medical Surgery in Primates, Vol. 1, pp. 372-378. Lyon.

Michejda M, Lamey, D (1971) Flexion and metric age changes of the cranial base in the Macaca mulatta. Infants and juveniles. Folia Primatol 34, 133-141.

Morriss-Kay GM, Wilkie AO (2005) Growth of the normal skull vault and its alteration in craniosynostosis: insights from human genetics and experimental studies. J Anat 207, 637-653.

Moss ML (1997a) The functional matrix hypothesis revisited. 1. The role of mechanotransduction. Am J Orthod Dentofacial Orthop 112, 8-11.

Moss ML (1997b) The functional matrix hypothesis revisited. 4. The epigenetic antithesis and the resolving synthesis. Am J Orthod Dentofacial Orthop 112, 410-417.

Moss ML, Young RW (1960) A functional approach to craniology. Am J Phys Anthropol 18, 281-292.

Opperman LA (2000) Cranial sutures as intramembranous bone growth sites. Dev Dyn 219, 472-485.

Ovchinnikov DA, Deng JM, Ogunrinu G, Behringer RR (2000) Col2a1-directed expression of Cre recombinase in differentiating chondrocytes in transgenic mice. Genesis 26, 145-146.
Parsons TE, Kristensen E, Hornung L, et al. (2008) Phenotypic variability and craniofacial dysmorphology: increased shape variance in a mouse model for cleft lip. J Anat (in press).

Petersson S, Persson AS, Johansen JE, et al. (2003) Truncation of the Shaker-like voltage-gated potassium channel, Kv1.1, causes megencephaly. Eur J Neurosci 18, 3231-3240.

Ravosa MJ (1991a) Ontogenetic perspective on mechanical and nonmechanical models of primate circumorbital morphology. Am J Phys Anthropol 85, 95-112.

Ravosa, MJ (1991b) Interspecific perspective on mechanical and nonmechanical models of primate circumorbital morphology. Am J Phys Anthropol 86, 369-396.

Ravosa MJ, Shea BT (1994) Pattern in craniofacial biology: evidence from the Old World monkeys (Ceropithecidae). Int J Primatol 15, 801-822.

Ross C, Henneberg M (1995) Basicranial flexion, relative brain size, and facial kyphosis in Homo sapiens and some fossil hominids. Am J Phys Anthropol 98, 575-593.

Ross C, Ravosa MJ (1993) Basicranial flexion, relative brain size, and facial kyphosis in nonhuman primates. Am J Phys Anthropol 91, 305-324.

Ross CF, Henneberg M, Ravosa MJ, Richard S (2004) Curvilinear, geometric and phylogenetic modeling of basicranial flexion: is it adaptive, is it constrained? J Hum Evol 46, 185-213.

Sansal I, Sellers WR (2004) The biology and clinical relevance of the PTEN tumor suppressor pathway. J Clin Oncol 22, 2954-2963.

Scott JH (1958) The cranial base. Am J Phys Anthropol 16, 319-348.

Spoor CF (1997) Basicranial architecture and relative brain size of Sts 5 (Australopithecus africanus) and other Plio-Pleistocene hominids. S Afr J Sci 93, 182-186.

Spoor F, O'Higgins P, Dean C, Lieberman DE (1999) Anterior sphenoid in modern humans. Nature 397, 572.

Strait D, Ross, CF (1999) Kinematic data on primate head and neck. Am J Phys Anthropol 108, 205-222.

Strait DS (1999) The scaling of basicranial flexion and length. J Hum Evol 37, 701-719.

Virchow RL (1857) Untersuchungen über die Entwicklung des Schädelgrundes. G. Reimer, Berlin.

Vogel C (1964) Uber eine Schadelbasisanomalie bei einem in freier Wildbahn geschossen Cercopithecus torquatus atys. Z Morphol Anthropol 55, 262-276.

Weidenreich F (1941) The brain and its rôle in the phylogenetic transformation of the human skull. Trans Am Philos Soc 31, 328442.

Whittingham MJ, Stephens PA, Bradbury RB, Freckleton RP (2006) Why do we still use stepwise modelling in ecology and behaviour? J Anim Ecol 75, 1182-1189.

Young NM, Wat S, Diewert VM, Browder LW, Hallgrimsson B (2007) Comparative morphometrics of embryonic facial morphogenesis: implications for cleft-lip etiology. Anat Rec (Hoboken) 290, 123139.

Yu JC, McClintock JS, Gannon F, Gao XX, Mobasser JP, Sharawy M (1997) Regional differences of dura osteoinduction: squamous dura induces osteogenesis, sutural dura induces chondrogenesis and osteogenesis. Plast Reconstr Surg 100, 23-31. 